\title{
Additive Manufactured A357.0 Samples Using the Laser Powder Bed Fusion Technique: Shear and Tensile Performance
}

\author{
Lucia Denti \\ Department of Engineering "Enzo Ferrari”, University of Modena and Reggio Emilia, Via Vivarelli 10, \\ 41125 Modena, Italy; lucia.denti@unimore.it; Tel.: +39-059-205-6100
}

Received: 26 July 2018; Accepted: 24 August 2018; Published: 27 August 2018

\begin{abstract}
New aluminium alloys, with lower silicon content than in the first-developed formulations, have recently been introduced in the field of Additive Manufacturing and are dedicated to automotive applications. As they are relatively new, mechanical characterization under standard protocols of the automotive field are of utmost scientific as well as industrial relevance. The paper addresses the mechanical properties and microstructure of A357.0. Static tensile and shear tests of samples built by Laser Powder Bed Fusion, with different orientations in the machine work volume, have been performed. The aim was to identify possible anisotropy in the tensile and shear behaviour of this innovative alloy. Particularly for shear, the effect of adhesion between the layers onto shear strength was studied. Results analysis, by means of statistical tools, allows for the affirmation that no tensile modulus or yield strength anisotropy is observed. Instead, a small (yet statistically significant) increase in both shear- and tensile strength and a decrease in ductility are obtained as the direction of the specimens approaches the growth direction. Scanning Electron Microscope (SEM) observation of the failure mechanisms assisted in the interpretation of the results, by relating different failure modes to the relative orientation of loads versus the directions of inherent anisotropy in Laser Powder Bed Fusion processes.
\end{abstract}

Keywords: additive manufacturing; laser powder bed fusion; A357.0; mechanical performance

\section{Introduction}

Over the next few years, the Additive Manufacturing (AM) industry is expected to continue to grow strongly. Oerlikon group, one of the major suppliers of metal powders for AM, forecasted that by 2021 the sale of AM products and services will be around 26.5 billion USD (United States dollars). AM has great potential, and is gaining every day in broader usage. In order to accelerate the adoption of AM, improvements in areas such as new material formulations and more solid knowledge of the expected mechanical behaviour will need to take place [1].

The formulations of aluminium (Al) alloys that are available for AM, and more specifically for Laser Powder Bed Fusion (LPBF), are still very few. Al alloys have been introduced for AM applications recently because, if compared for example to Ti alloys, they are easier to machine by means of conventional subtractive processes. However, since $\mathrm{Al}$ is comparatively cheaper to purchase, the material saving that is allowed by AM becomes less impressive. As a consequence, the production of Al parts by LPBF has less immediate commercial appeal [2].

Other obstacles to the use of $\mathrm{Al}$ alloys are:

- The presence of some heavily applied hardenable alloy elements (such as $\mathrm{Zn}$ ), which leads to turbulent melt pools, splatter, and porosity [2]. Many formulations are not suitable for or easy to be used in LPBF; 
- High reflectivity;

- Poor flowability, which can impede the deposition of a smooth thin layer [3];

- The low viscosity of the molten material limits the melt pool sizes.

Currently, the most common aluminium alloy for LPBF is AlSi10Mg. It is used to produce parts with high strength and high dynamic loadability. The use of such parts in the aerospace and automotive industries is quickly spreading [4].

As previously mentioned, much is expected from the market in terms of a wider range of aluminium alloys to be processed by LPBF. For example, a specific alloy has been introduced recently: Scalmalloy ${ }^{\circledR} \mathrm{RP}$ is the Airbus Group's unique aluminium-magnesium-scandium alloy (AlMgSc). It was developed for additive manufacturing and displays high strength [5]. On the side of high-performance alloys, the new A20X ${ }^{\mathrm{TM}}$ was patented in 2010 and gained full aerospace approval in 2012 [6]. The formulation consists of an aluminium copper base, with the addition of intermetallic titanium diboride. The resulting ultra-fine microstructure accomplishes strength values as high as $477 \mathrm{MPa}$, together with the possibility to operate at high temperatures. Initially developed for casting, the alloy in now available for use in powder bed AM.

Also, a new formulation of an Al-Si-Mg alloy has been marketed of late: A357.0, in which the Si content is reduced to $7 \mathrm{wt} \%$ [7-9]. The alloy proposed by CITIM GmbH ensures, as an example, a nominal strength of $415 \mathrm{MPa}$ and a total extension at fracture of $5 \%$ in the as-built state [9]. A357.0 is of special interest for automotive applications since the same alloy is commonly used for many car body parts produced by traditional processes. Typical examples are brackets, carters, and stands. The quality standards of high-performance cars require the adoption of expensive solutions, mainly gravity and low-pressure permanent mould casting, with the use of cores. While outstanding as to mechanical and dimensional quality of parts, as well to absence of defects, such processes suffer from high investment costs, long time-to-market, and very low flexibility. Such process characteristics mismatch production types characterized by very small batches. In the case of small batch, variable cost, still high, can be much easier attributed than fixed ones. LPBF processes are an increasingly frequent choice for many aluminium components traditionally obtained by casting. Yet, LPBF is still at the early stages in this field as the reliability and predictability of a technology that only recently included aluminium alloys among the options is still unproven. The choice of an innovative process with a known material means the same target material can be kept. As an advantageous consequence, the complex structural validations of a part design (including static, dynamic, durability, and non-linear crash load cases) do not need to be rerun.

Data on the mechanical performance of Al-based materials used in LPBF are often not comparable directly due to the non-homogeneity of the characterization standards that are used and the effect of different process parameters that cause a great dispersion of data. Table 1 lists the mechanical properties available in the datasheets for the as-built condition.

Moreover, the difficulty in data collection increases for the most recently marketed materials. AlSi10Mg has been studied for a while, and at least its static properties are quite consolidated. Some authors also addressed the optimization of process parameters, providing information such as the effect of power on the build rate and the combination of power and volumetric energy density for best process performance [13]. The higher-silicon alloy Al-12Si has been studied by Prashanth et al., who provided an extremely interesting focus on mechanical properties and their relation to the microstructure in different build orientations [14]. Prashanth and colleagues observed a remarkably fine grain structure, along with outstanding strength, at least twice that of the cast material. Low silicon aluminium alloys are still quite new in the field of LPBF and very little tested [6,7]. For most of the major system suppliers, A357.0 is still under development and is expected to reach full commercial availability soon. 
Table 1. Mechanical performance specified by the suppliers of Aluminium alloys used for Laser Powder Bed Fusion (LPBF) in the as-built condition.

\begin{tabular}{|c|c|c|c|c|c|c|c|}
\hline \multirow{2}{*}{$\begin{array}{c}\begin{array}{c}\text { Mechanical } \\
\text { Performance }\end{array} \\
\text { Direction }\end{array}$} & \multicolumn{2}{|c|}{ Tensile Strength [MPa] } & \multicolumn{2}{|c|}{ Yield Strength [MPa] } & \multirow[t]{2}{*}{$\begin{array}{c}\text { Modulus of } \\
\text { Elasticity [GPa] }\end{array}$} & \multicolumn{2}{|c|}{$\begin{array}{c}\text { Total Extension at } \\
\text { Fracture }[\%]\end{array}$} \\
\hline & $X Y$ direction & $Z$ direction & $X Y$ direction & $Z$ direction & & $X Y$ direction & $Z$ direction \\
\hline AlSi10Mg [10] & $460 \pm 20$ & $470 \pm 20$ & $270 \pm 20$ & $230 \pm 20$ & $70 \pm 10$ & $9 \pm 2$ & $6 \pm 2$ \\
\hline AlSi10Mg [11] & \multicolumn{2}{|c|}{$397 \pm 11$} & \multicolumn{2}{|c|}{$227 \pm 11$} & $64 \pm 10$ & \multicolumn{2}{|c|}{$6 \pm 1$} \\
\hline AlSi9Cu3 [9] & \multicolumn{2}{|c|}{$380 \pm 40$} & \multicolumn{2}{|c|}{$200 \pm 40$} & $62 \pm 10$ & \multicolumn{2}{|c|}{$2.5 \pm 1.0$} \\
\hline AlSi9Cu3 [11] & \multicolumn{2}{|c|}{$415 \pm 15$} & \multicolumn{2}{|c|}{$236 \pm 8$} & $57 \pm 5$ & \multicolumn{2}{|c|}{$5 \pm 1$} \\
\hline AlSi12 [11] & \multicolumn{2}{|c|}{$409 \pm 20$} & \multicolumn{2}{|c|}{$211 \pm 20$} & & \multicolumn{2}{|c|}{$5 \pm 3$} \\
\hline AlSi7Mg [9] & \multicolumn{2}{|c|}{$410 \pm 50$} & \multicolumn{2}{|c|}{$270 \pm 50$} & $70 \pm 15$ & \multicolumn{2}{|c|}{$5 \pm 3$} \\
\hline AlSi7Mg [11] & \multicolumn{2}{|c|}{$375 \pm 17$} & \multicolumn{2}{|c|}{$211 \pm 15$} & $59 \pm 21$ & \multicolumn{2}{|c|}{$8 \pm 2$} \\
\hline Scalmalloy ${ }^{\circledR}[5]$ & \multicolumn{2}{|c|}{520} & \multicolumn{2}{|c|}{470} & & \multicolumn{2}{|c|}{13} \\
\hline $\mathrm{A} 20 \mathrm{X}^{\mathrm{TM}}[6]$ & \multicolumn{2}{|c|}{477} & \multicolumn{2}{|c|}{415} & & \multicolumn{2}{|c|}{13} \\
\hline
\end{tabular}

${ }^{1}$ After stress-relieving.

This paper is focused on the characterization of ISO A357.0 parts (ASM, ASTM, and SAE 356.0 specifications) produced by LPBF. This alloy is traditionally used for applications in which good weldability, pressure tightness, and good resistance to corrosion are required. Some of the many examples of its use may include pump parts of aircrafts, automotive transmission cases, aircraft fittings and control parts, as well as water-cooled cylinder blocks. Many of the listed applications involve the production of big parts, so the present contribution was focused specifically on verifying the properties expected for large components to be produced relatively quickly. As a consequence, the following choices were made in the research plan, namely: (i) to use one of the machines with the biggest build chamber on the market; (ii) to select high-productivity process parameters in order for the process to be economically viable; (iii) to use a sufficiently high plate temperature so that distortion even of big parts would not be an issue and stress-relieving would not be required; and iv) to disregard any possible subsequent densification steps, as for example hot isostatic pressing, because it would hamper the industrial benefits of the solution under investigation.

The aim of the research is to evaluate the tensile and shear behaviour of this new alloy and to verify if different build orientations cause a quantitative variation of the mechanical properties and a qualitative change of the failure modes.

\section{Materials and Methods}

A357.0 powder was used to produce tensile and shear specimens. Of the powder, the nominal chemical composition versus the experimental one is listed in Table 2, and the particle size measured by the supplier by laser granulometry is shown in Figure 1 [12].

Table 2. Nominal chemical analysis of the A357.0 powder [12].

\begin{tabular}{ccccccc}
\hline \multirow{2}{*}{ Weight \% } & Si & Mg & Fe & Zn & Ti & Al \\
\cline { 2 - 7 } & 7.2 & 0.51 & 0.19 & 0.02 & 0.09 & bal. \\
\hline
\end{tabular}




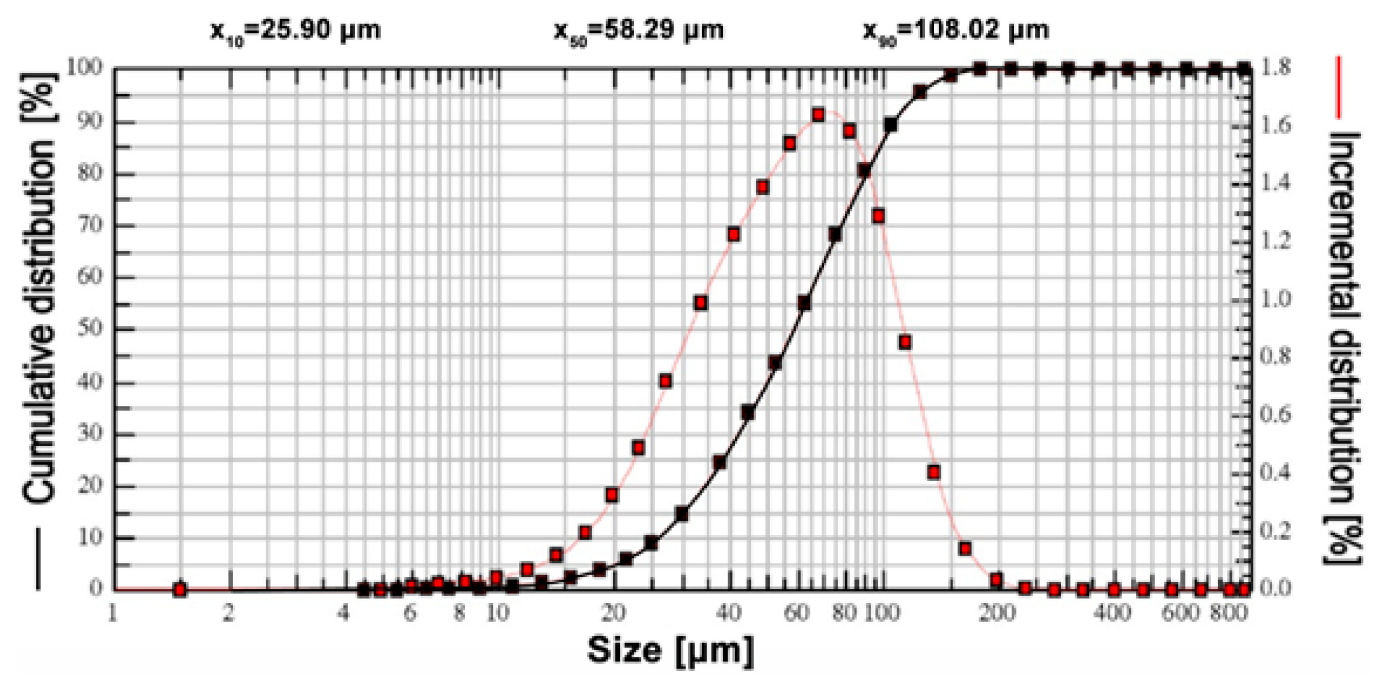

Figure 1. Particle size measured by laser granulometry [12].

The A357.0 powder used in this paper was observed by scanning electron microscope, SEM (ESEM, Quanta-200, FEI, Thermo Fisher Scientific, Eindhoven, The Netherland), equipped with an X-ray energy dispersion spectroscopy system (X-EDS, INCA Oxford Instruments, Abingdon, UK) in order to check the particle shape and the chemical composition.

The specimens were manufactured by means of an X Line $2000 \mathrm{R}$ (Concept Laser GmbH, Lichtenfels, Germany) by using the following process parameters:

- $\quad$ Laser power: $950 \mathrm{~W}$;

- Laser velocity: $2000 \mathrm{~mm} / \mathrm{s}$;

- Laser spot: $400 \mu \mathrm{m}$;

- Hatch distance: $0.2 \mathrm{~mm}$;

- Inert gas: nitrogen;

- Platform temperature: preheated at $200^{\circ} \mathrm{C}$;

- Scan strategy: skin-core;

The machine has one of the largest build chambers on the market $\left(800 \times 400 \times 500 \mathrm{~mm}^{3}\right)$ and is specifically dedicated to the manufacture of large functional components with extremely high productivity. The system is equipped with two fibre lasers that each output $1000 \mathrm{~W}$, an automated powder transport, and a rotating mechanism so that two build modules can be used reciprocally, without any downtime.

Heating of the platform acts as an 'in-process' ageing treatment [7] and allows for the limitation of the cooling rates and the residual stresses as compared to unheated builds [6], hence the parts do not require any stress relieving treatment. All the specimens in this study were tested and observed in the as-built condition.

Shear tests were performed according to ASTM B831-05, by adopting a test velocity of $1 \mathrm{~mm} / \mathrm{min}$ (the standard cross head speed rate limit is $19.1 \mathrm{~mm} / \mathrm{min}$ ). Such speed allowed for a stress rate lower than $689 \mathrm{MPa} / \mathrm{min}$, which is the standard loading rate limit on the cross-section. The shear specimens were built in the LPBF machine as rectangular parallelepipeds and then machined to the final geometries, as in Figure 2A.

Tensile tests were performed according to UNI EN ISO 6892-1 by adopting a strain rate of $0.00025 \pm 0.00005 \mathrm{~s}^{-1}$, which was achieved using a test velocity of $0.5 \mathrm{~mm} / \mathrm{min}$. The mechanical tests were preceded by a calibration test with an initial velocity of $1.0 \mathrm{~mm} / \mathrm{min}$. Strain was measured by an extensometer with a gauge length of $25 \mathrm{~mm}$. The tangent tensile modulus was automatically 
calculated by the machine software. The tensile specimens were built in the LPBF machine as $14 \mathrm{~mm}$ diameter and $80 \mathrm{~mm}$ long cylinders and were then machined to the final geometry shown in Figure $2 \mathrm{~B}$.

Tensile and shear specimens were built in different orientations relative to the LPBF process. Figure 3 shows the build orientations of samples parallel to the layers $\left(0^{\circ}\right)$, parallel to the growth direction $\left(90^{\circ}\right)$, and inclined at $45^{\circ}$ with respect to both previous directions $\left(45^{\circ}\right)$. In the case of $45^{\circ}$ shear specimens, specific attention has been paid to test interlayer shear strength; the geometry and orientation of the specimens allowed for the application of the shear loads on a surface which is parallel to the powder bed (Figure 3). Figure 3 also shows the direction along which the recoater blade spreads the powder in the bed, and the direction of the inert gas flux on the powder bed. The latter is very important in order to blow the melting slags away from the build area.

The number of specimens used in each test is shown in Table 3.

A)

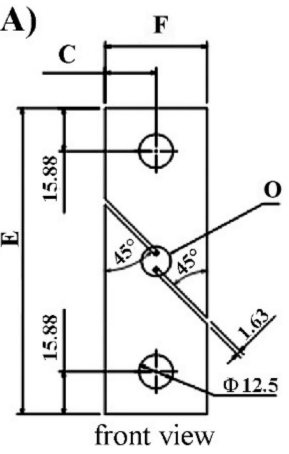

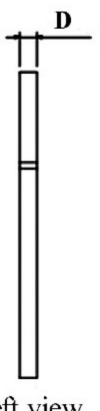

left view

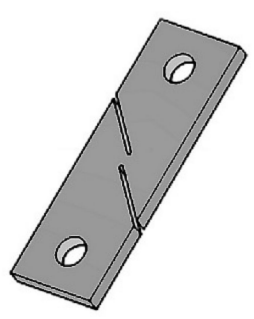

isometric view
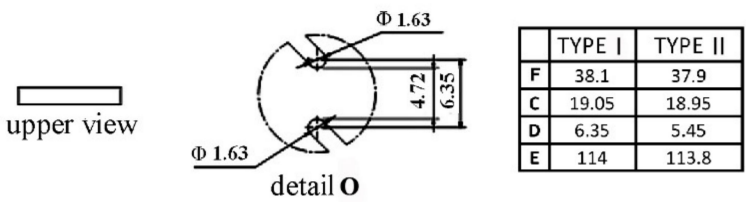

B)
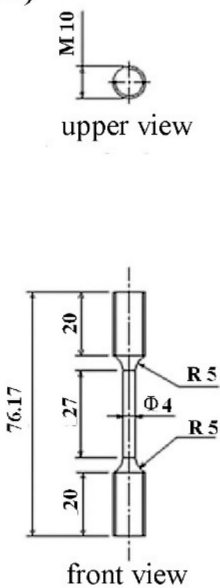

front view

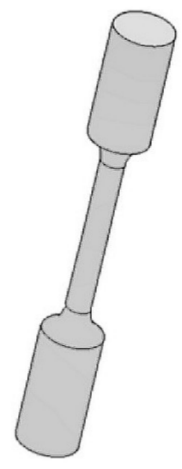

isometric view

Figure 2. Geometry of the used specimens: (A) shear, ASTM B831-05 type I and type II; (B) tensile, UNI EN ISO 6892-1.

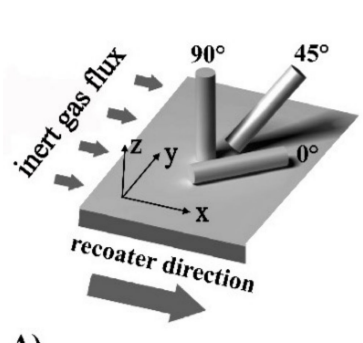

A)

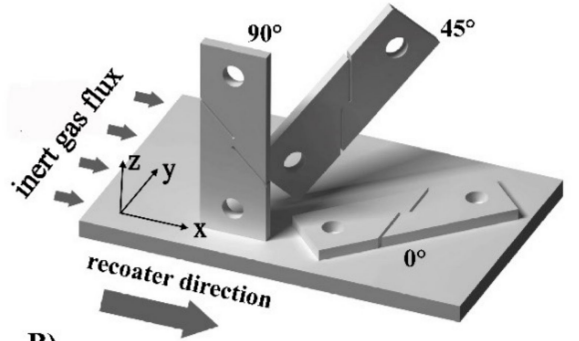

B)

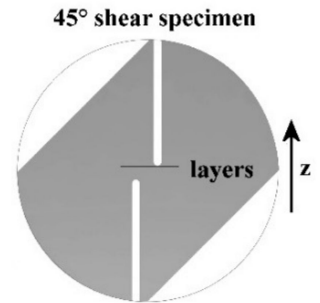

C)

Figure 3. Orientation of the built specimens: (A) tensile specimens; (B) shear specimens; (C) detail of $45^{\circ}$ shear specimen.

Table 3. Number of specimens used in the tests.

\begin{tabular}{|c|c|c|c|}
\hline Specimens Tested & $\begin{array}{l}\text { No. of Specimens in } \\
0^{\circ} \text { Direction }\end{array}$ & $\begin{array}{c}\text { No. of Specimens in } \\
45^{\circ} \text { Direction }\end{array}$ & $\begin{array}{c}\text { No. of Specimens in } \\
90^{\circ} \text { Direction }\end{array}$ \\
\hline $\begin{array}{l}\text { ASTM B831-05 } \\
\text { Figure } 2 \text { type I }\end{array}$ & 9 & 9 & - \\
\hline $\begin{array}{l}\text { ASTM B831-05 } \\
\text { Figure } 2 \text { type II }\end{array}$ & 8 & 8 & 17 \\
\hline UNI EN ISO 6892-1 & 17 & 17 & 17 \\
\hline
\end{tabular}


Brinell hardness HBW 2.5/62.5/15 hardness (ball diameter $2.5 \mathrm{~mm}$, applied force $62.5 \mathrm{kgf}$, duration time $15 \mathrm{~s}$ ) was measured according to standard EN ISO 6506-1. The tests were carried out on a surface parallel to the powder bed as well as on one parallel to the growth direction. Metallographic sections of the specimens, parallel to the $X Y, X Z$, and $Y Z$ planes, were prepared by means of microcutting, embedding in epoxy resin, and polishing with a $3 \mu \mathrm{m}$ diamond suspension. Residual porosity was measured by image analysis on polished sections using an optical microscope, OM (Eclipse LV150N, Nikon, Tokyo, Japan). Metallurgical structures were observed after etching with the Dix-Keller reactant ( $\mathrm{HF} 2 \%$ vol, $\mathrm{HCl} \mathrm{1.5 \%} \mathrm{vol,} \mathrm{HNO}_{3} 2.5 \%$ vol; water bal.). The etched surfaces were observed by an OM as well as by an Nova NanoSEM 450 FEG-SEM (FEI, Thermo Fisher Scientific, Eindhoven, The Netherland) in immersion lens mode.

Rupture surfaces of all specimens were observed by SEM with the aid of X-ray energy dispersion spectroscopy (X-EDS) analysis (X-EDS, INCA Oxford Instruments, Abingdon, UK).

\section{Results and Discussion}

Figure 4 shows SEM images of the A357.0 powder used in this paper, sampled from the build chamber after the job completion. The sphericity of powder particles is not as regular or repetitive as that of other raw materials for LPBF. Irregular shape and poor flowability are among the well-known intrinsic difficulties in working with aluminium [3,7]. The same is not true, for example, for titanium or Ni-based alloys. The shape of the A357.0 particles may have an effect on the flowability of the powder and lead to a lack of continuity in the distributed powder layer. Table 4 shows the chemical composition measured on the powder by means of an X-ray energy dispersion spectroscopy system. No traces of contaminants were detected, even when several powder specimens were observed and a careful investigation of possible impurities was carried out. The chemical composition was consistent with the nominal one listed in Table 2. As far as the relatively high oxygen content is concerned, it should be considered that the powder was not kept in an inert atmosphere after extraction from the machine, during SEM specimen preparation. In order to cross-check the oxygen percentage in the consolidated specimens, a sample was ground and polished in such a way as to remove the outer oxidised layers and was immediately introduced in the SEM chamber, ensuring the shortest possible contact with air. The X-EDS spectrum and the chemical composition detected on this sample are shown in Figure 5, where an oxygen percentage of $1.3 \%$ is reported.
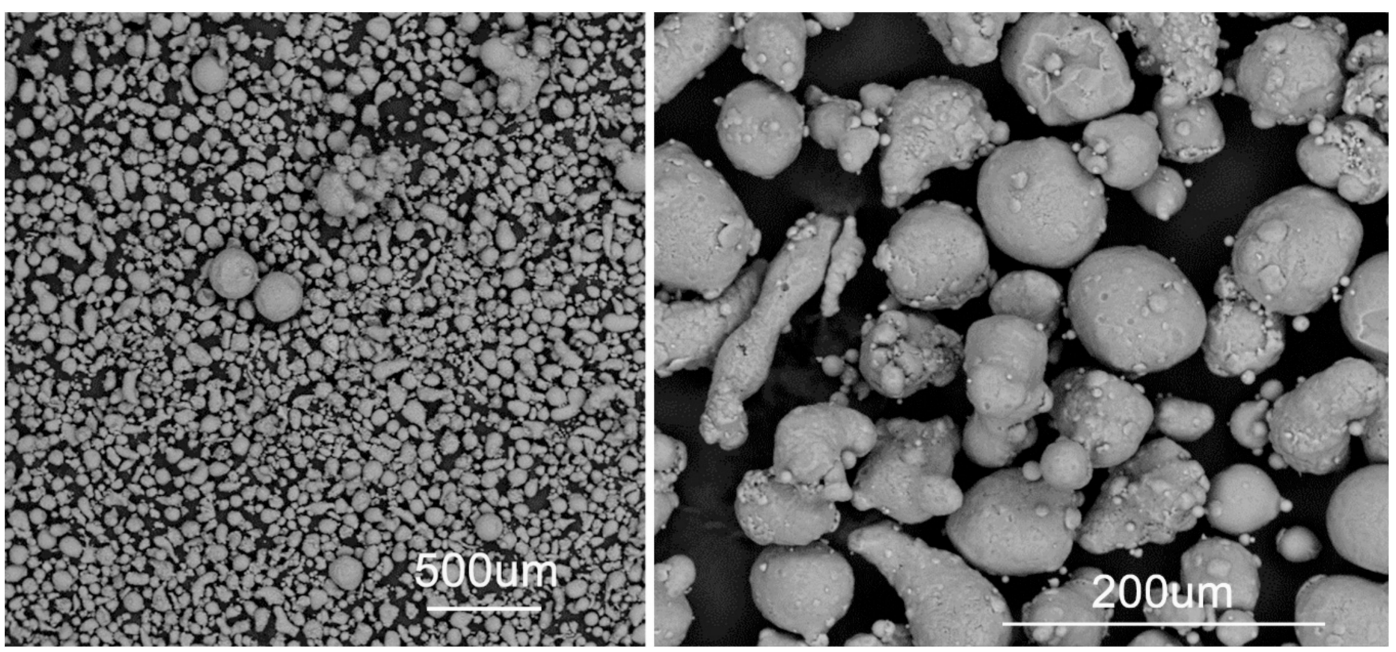

Figure 4. A357.0 powder. 
Table 4. Experimental chemical analysis of the A357.0 powder after job completion.

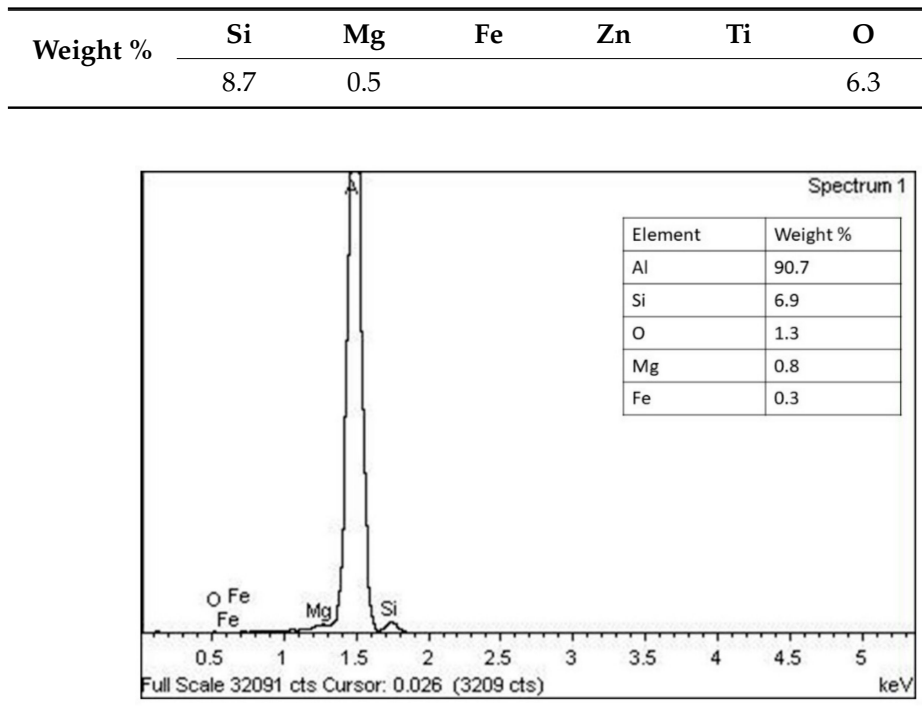

Figure 5. X-ray energy dispersion spectroscopy (X-EDS) spectrum and quantitative element percentage of a freshly polished surface of a tensile specimen.

The residual porosity measured on five images, such as the example in Figure 6, is on average $0.69 \%$, with a standard deviation of $0.28 \%$. A final density of $99.3 \%$ has thus been achieved, which is consistent with common industrial specifications. The microstructure obtained in the three orientations can be appreciated in Figure 7, where OM images are illustrated next to FEG-SEM ones. A very fine cellular structure is observed, equiaxed in the $X Y$ plane (Figure $7 \mathrm{~A}$ ) and elongated in the $Z$ direction (Figure 7B,C), comparable to the 'fibre texture' observed by Prashanth et al. for Al-12Si [14] and by Hadadzadeh et al. for AlSi10Mg [15]. Hadadzadeh and colleagues produced extremely interesting proofs that when the building direction changes from vertical to horizontal, a columnar to equiaxed transition is obtained in the AlSi10Mg alloy produced by LPBF. The microstructure observed in this study could be consistent with this claim.

HBW hardness was 95.2 (Standard Deviation, SD 1.3) on the surface parallel to the powder bed and 102.6 (SD 0.8) on the one parallel to the $Z$ direction.

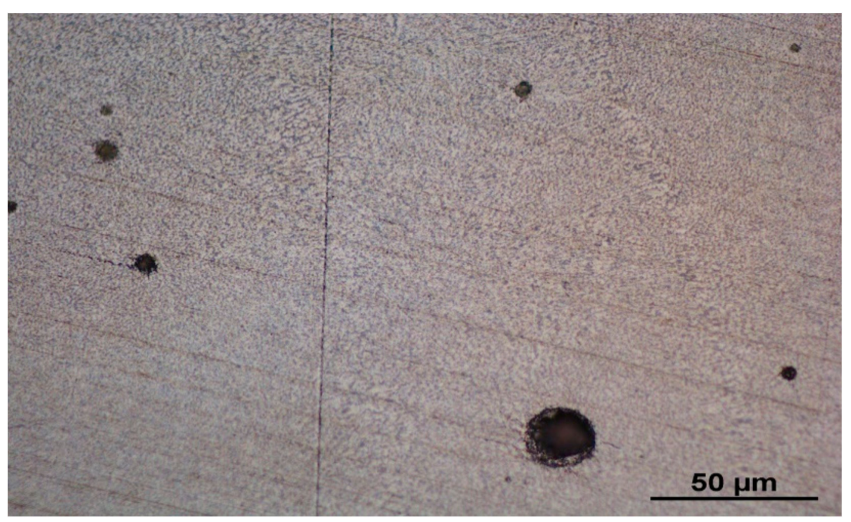

Figure 6. Optical microscope $(\mathrm{OM})$ image of a polished section for the measurements of residual porosity.

The results of all the mechanical tests are listed in Table 5 and shown in Figures 8 and 9. They include: elastic modulus $(E)$, yield strength $\left(R p_{0.2}\right)$, tensile strength $\left(R_{m}\right)$, percentage total extension at fracture $\left(A_{t}\right)$, and shear strength $(S)$. 

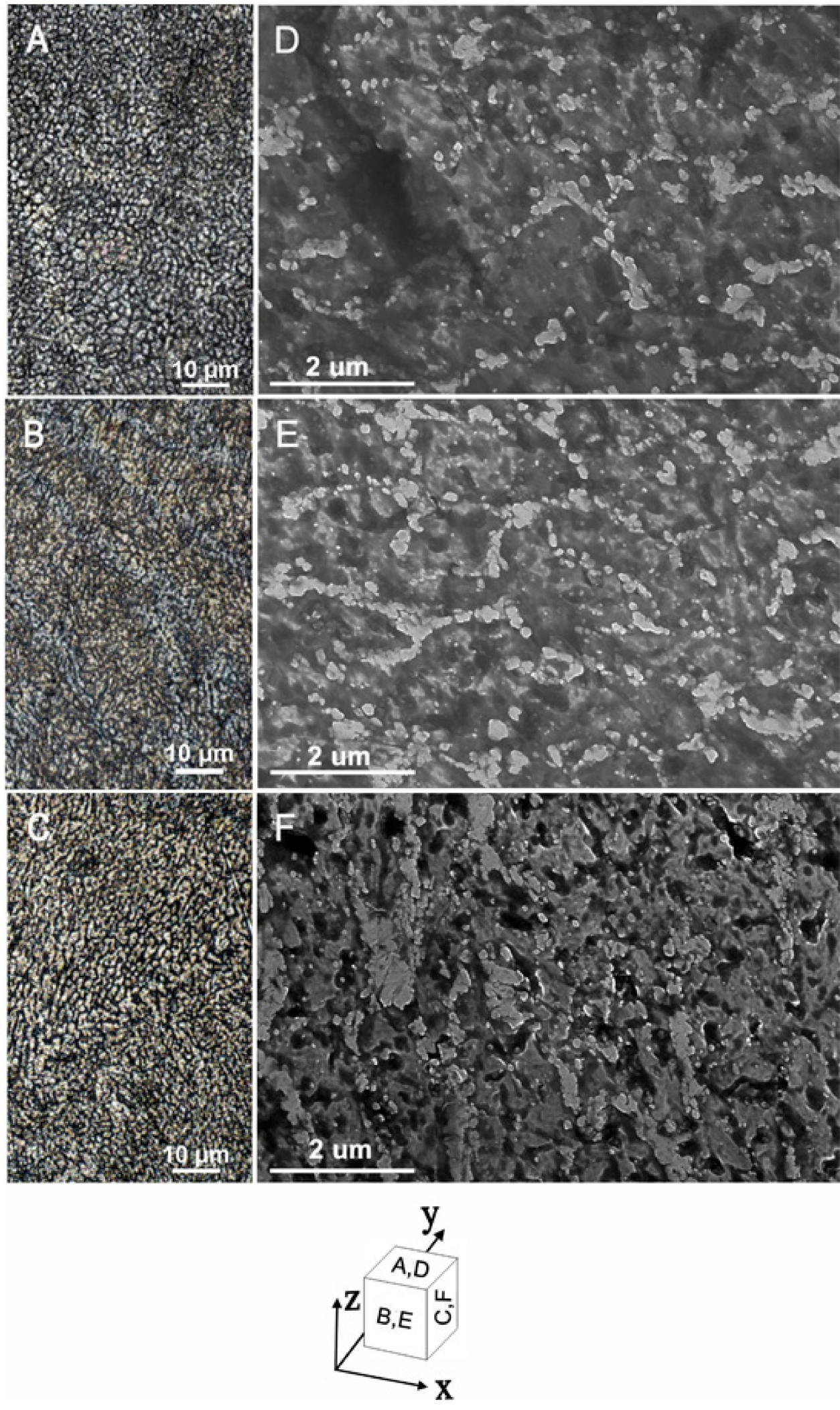

Figure 7. OM (A-C) and FEG-SEM (D-F) images of etched sections parallel to: the $X Y$ plane (A,D); the $X Z$ plane $(\mathbf{B}, \mathbf{E})$ and the $Y Z$ plane $(\mathbf{C}, \mathbf{F})$.

No distinction in the mechanical behaviour was observed between shear specimens produced with the dimensions labelled as Type I and II in Figure 2. Hence, the results of the shear tests and 
the observation of the rupture surfaces are presented and discussed jointly in this section. The yield-, tensile-, and shear strength (the obtained values are the average of 17 measurements) rise when the direction of the specimens approaches the growth direction, but the deviation between different orientations is quite small. The opposite trend is observed for extension, but in this case the variation is much bigger. The elastic modulus does not show any relevant trend for varying orientation. The results for strength are in contrast with those obtained by other authors for Al-12Si; in that case, the effect of texture proved negligible on the yield strength, which was found to be unaffected by the build orientation [14].

Table 5. Results of the tensile and shear tests. Standard deviation is between brackets. $\mathrm{E}=$ elastic modulus, $\mathrm{Rp}_{0.2}=$ yield strength, $\mathrm{R}_{\mathrm{m}}=$ tensile strength, $\mathrm{A}_{\mathrm{t}}=$ percentage total extension at fracture, and $S=$ shear strength.

\begin{tabular}{cccc}
\hline Tensile and Shear Test Results & $\mathbf{0}^{\circ}$ & $\begin{array}{c}\mathbf{4 5}^{\circ} \\
\text { Mean (SD) }\end{array}$ & $\begin{array}{c}\mathbf{9 0}^{\circ} \\
\text { Mean (SD) }\end{array}$ \\
\hline $\mathrm{E}[\mathrm{GPa}]$ & $75.0(4.1)$ & $77.8(6.8)$ & $74.8(5.3)$ \\
$\mathrm{R}_{\mathrm{p} 0.2[\mathrm{MPa}]}$ & $184(17)$ & $195(17)$ & $192(17)$ \\
$\mathrm{R}_{\mathrm{m}}[\mathrm{MPa}]$ & $284(19)$ & $298(17)$ & $305(15)$ \\
$\mathrm{A}_{\mathrm{t}}[\%]$ & $6.5(0.8)$ & $5.1(0.8)$ & $3.5(0.7)$ \\
$\mathrm{S}[\mathrm{MPa}]$ & $165(10)$ & $173(9)$ & $192(9)$ \\
\hline
\end{tabular}
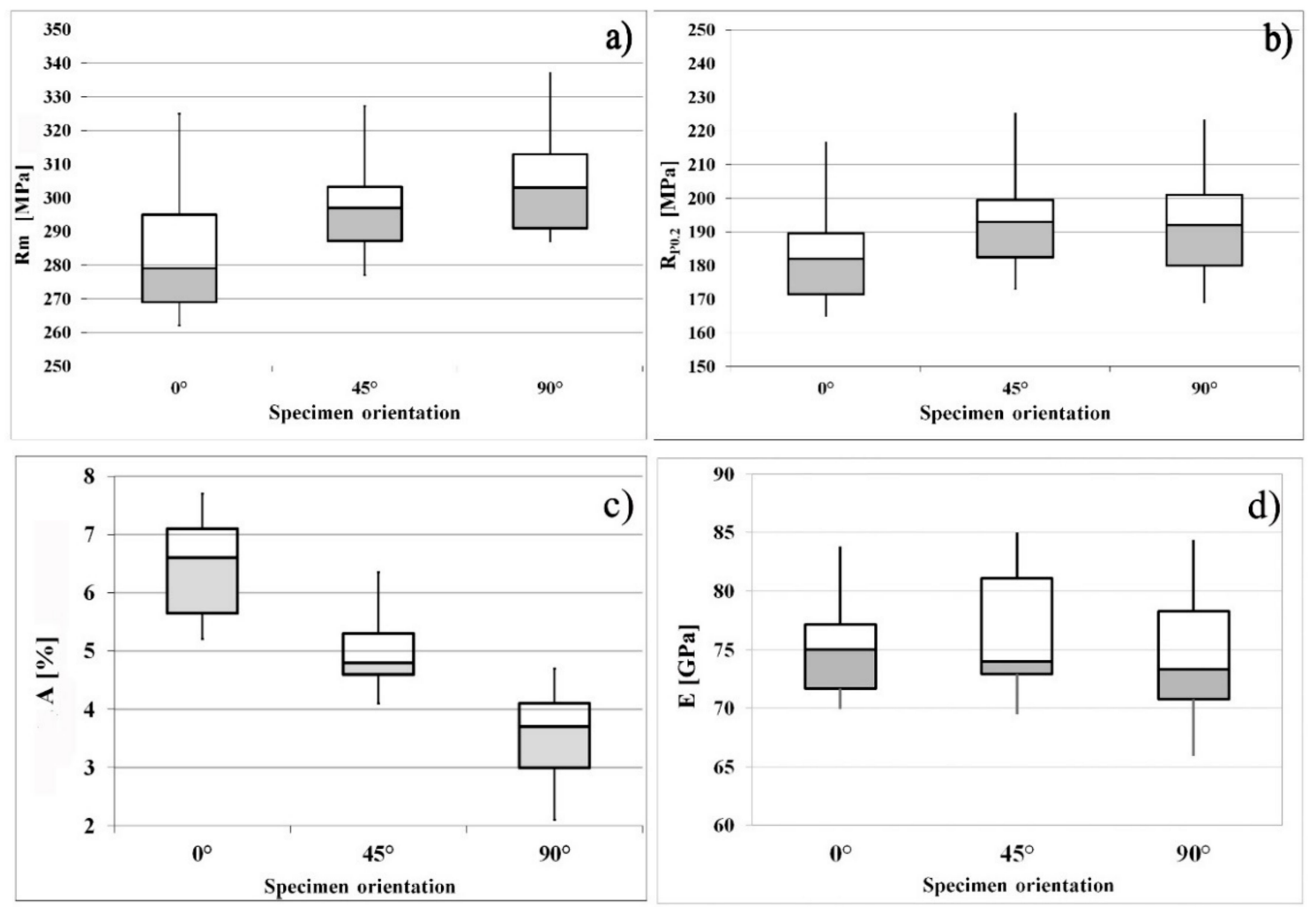

Figure 8. Tensile test results: (a) tensile strength values; (b) yield strength values; (c) percentage total extension at fracture values; (d) elastic modulus values. 


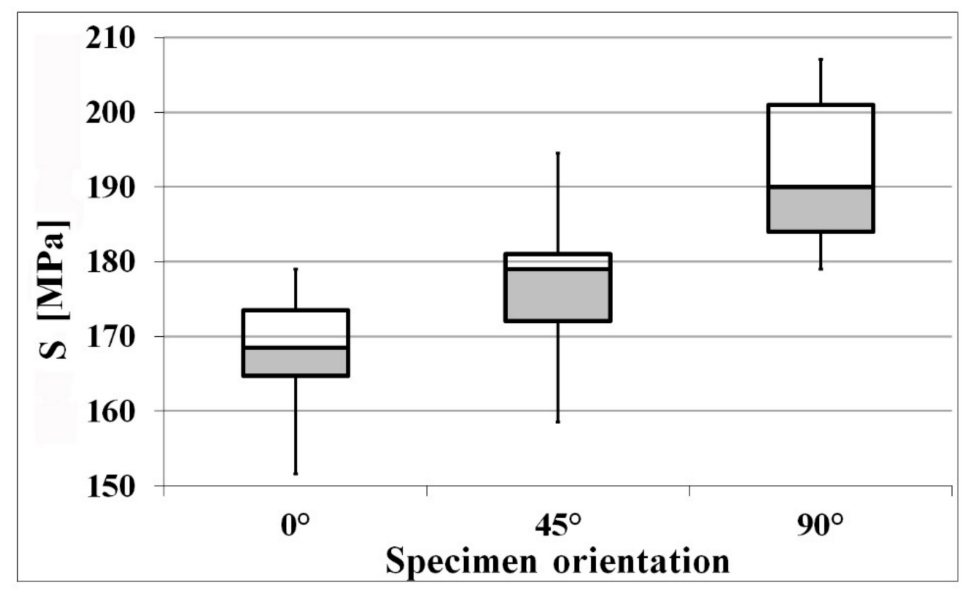

Figure 9. Shear strength results.

For the $90^{\circ}$ specimens, the yield and tensile strength values are in good agreement with those obtained by other authors who produced density optimised samples [16]. Rao et al. found a yield stress of $187 \mathrm{MPa}$ (vs $192 \pm 17 \mathrm{MPa}$ in this research) and an ultimate stress of $290 \mathrm{MPa}$ (vs $305 \pm 15 \mathrm{MPa}$ ). A comparison with the nominal datasheets should take into account that all the suppliers declare the mechanical properties either in the as-built condition (as summed in Table 1), or after the T6 heat treatment. The use of parts in the as-built state is unfeasible for many industrial applications, especially in the automotive field, due to excessive anisotropy, scarce ductility, and undue frozen stresses or post-build deformations. In the present paper, the aim was to study process conditions capable of minimizing shrinkage-related deformation even in the case of big components. Consequently, the temperature of the build plate was chosen so as to allow a continuous stress relief of the part during its construction. Therefore, comparatively lower values of yield and tensile strengths, against the data in Table 1, are not surprising. Conversely, the results of the tensile tests in this research are encouragingly comparable to the typical values of the mechanical properties of A357.0 obtained by casting and T6 heat treatment, shown in Table 6.

Anisotropy of mechanical performance, i.e., possible significant differences in the values that have been measured for the three orientations, was evaluated by statistical tools (Statistica 8, Statsoft, Hamburg, Germany). A correlation analysis was done of the independent variable 'orientation' on all the measured mechanical characteristics listed in Table 4. Table 7 registers the results, expressed in terms of correlation coefficients and probability values ( $p$-values). When lower than 0.05 , the $p$-values can be taken as a decision to reject the null hypothesis of insignificance of the correlation. A significant, even if slight, effect of orientation onto tensile and shear strength was observed. The same applies to total extension at break, but in this case a much greater variation was measured: ductility was nearly halved from $0^{\circ}$ to $90^{\circ}$. For elastic modulus and yield strength, instead, the variations are within the scattering of experimental data, since the associated $p$-values are much higher than 0.05 . As anticipated above, the same is true for shear strength of specimens produced with the two different thickness values (Types I and II): no differences are observed.

Failure mechanisms on rupture surfaces are expected to reflect the described anisotropy of strength and ductility.

Table 6. Typical mechanical properties of A357.0 aluminium alloy obtained by casting [17].

\begin{tabular}{cccccc}
\hline Alloy & Heat Treatment & $\mathbf{R m}[\mathrm{MPa}]$ & $\mathbf{R p}_{\mathbf{0 . 2}}[\mathrm{MPa}]$ & $\mathbf{A}[\%]$ & $\mathbf{S}[\mathrm{MPa}]$ \\
\hline A357.0 & $\mathrm{T} 6$ & 315 & 250 & 3 & 275 \\
\hline
\end{tabular}


Table 7. Correlation coefficients and $p$-values resulting from the correlation analysis for the variables E, $\mathrm{Rp}_{0.2}, \mathrm{Rm}, \mathrm{A}$, and $\mathrm{S}$ versus build orientation. Records below the level of significance of 0.05 are bold.

\begin{tabular}{cccccc}
\hline Correlation Analysis & $\mathbf{E}$ & $\mathbf{R p}_{\mathbf{0 , 2}}$ & $\mathbf{R m}$ & $\mathbf{A}[\%]$ & $\mathbf{S}$ \\
\hline Correlation coefficient & -0.02 & 0.19 & 0.51 & -0.85 & 0.78 \\
$p$-value & 0.882 & 0.189 & $2.26 \times 10^{-4}$ & $5.53 \times 10^{-14}$ & $6.41 \times 10^{-8}$ \\
\hline
\end{tabular}

The rupture surfaces have been observed by means of a SEM. Rupture surfaces obtained in the shear tests show that for specimens produced in all directions, shear rupture generates two distinct failure morphologies. Very fine dimple areas are adjacent to zones of shear flow where the material is dragged onto the surface (Figure 10). For $0^{\circ}$ and $90^{\circ}$ specimens, the dimples are parallel to the rupture surface, that is to say parallel to the images (Figure 10d,f), whereas specimens built at $45^{\circ}$, show only dimples pointing out of the rupture surface (Figure 10e). For these specimens, shear stresses are applied onto a plane that is parallel to the layers. A further distinction can be observed between $0^{\circ}$ and $90^{\circ}$ specimens. For $90^{\circ}$, dimples are parallel not only to the rupture surface, but also to the direction of the shear load. In addition, for $0^{\circ}$ specimens numerous areas of lack of fusion are detected, where unmolten powder particles are still present (Figure 11). An extremely fine fibre microstructure is clearly visible, composed of thin grains elongated by the $Z$ direction. The described morphology accounts for the differences measured for the shear strength. Namely, specimens built in the $0^{\circ}$ direction are the weakest, due to a combination of lack of fusion defects and ineffective orientation of the fibre structure versus the shear stresses. For $45^{\circ}$ specimens, the shear stresses act perpendicularly to the texture obtained by LPBF. Specimens produced in the $90^{\circ}$ orientation are the strongest since they benefit from shear loads acting along the direction of the fine elongated grain structure. An additional effect of higher percentage of columnar grains in $90^{\circ}$ specimens as compared to $0^{\circ}$ ones, similar to the findings by Hadadzadeh et al. [15], cannot be excluded.
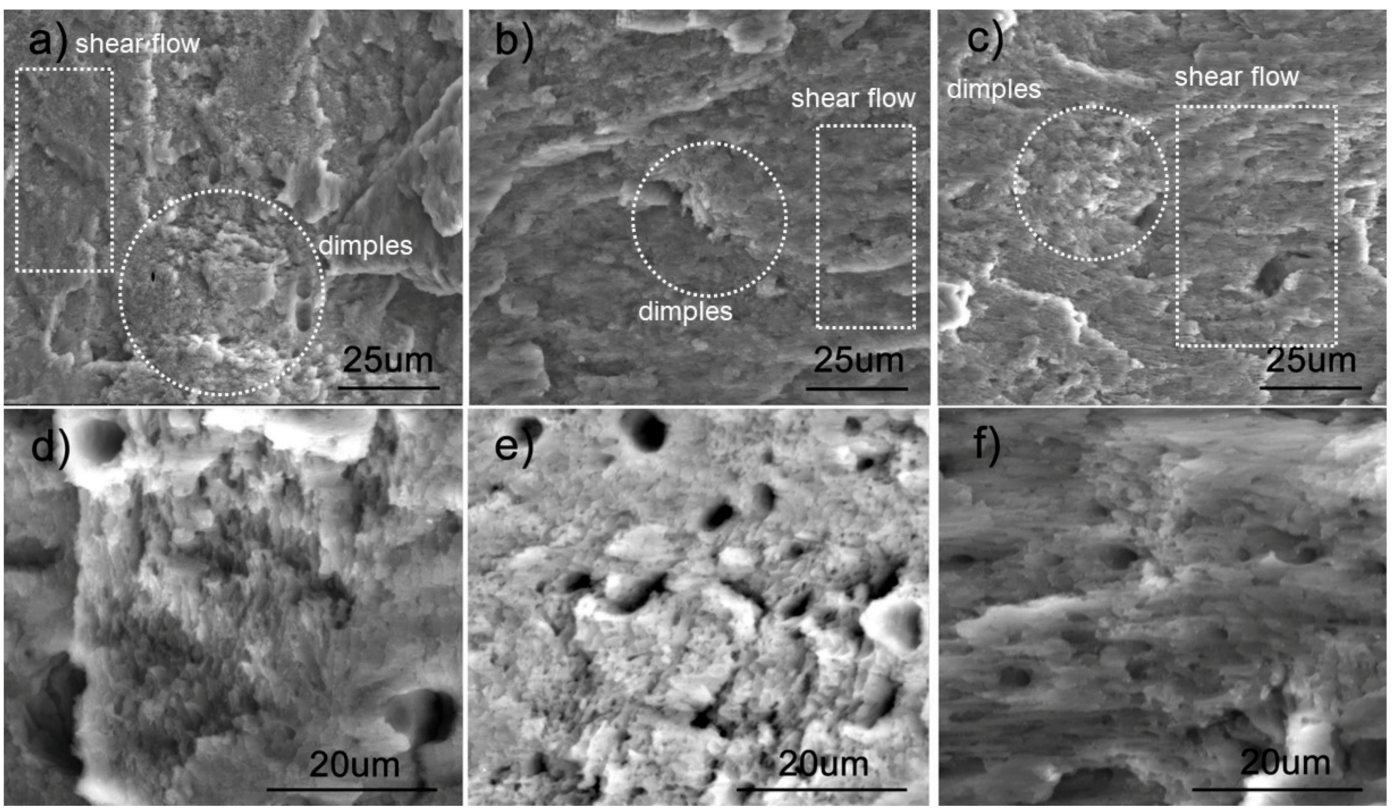

Figure 10. SEM observations of the rupture surface of A357.0 shear test specimens. The failure morphology changes with the growth direction of the specimen: $(\mathbf{a}, \mathbf{d}) 0^{\circ},(\mathbf{b}, \mathbf{e}) 45^{\circ}$, and $(\mathbf{c}, \mathbf{f}) 90^{\circ}$. 


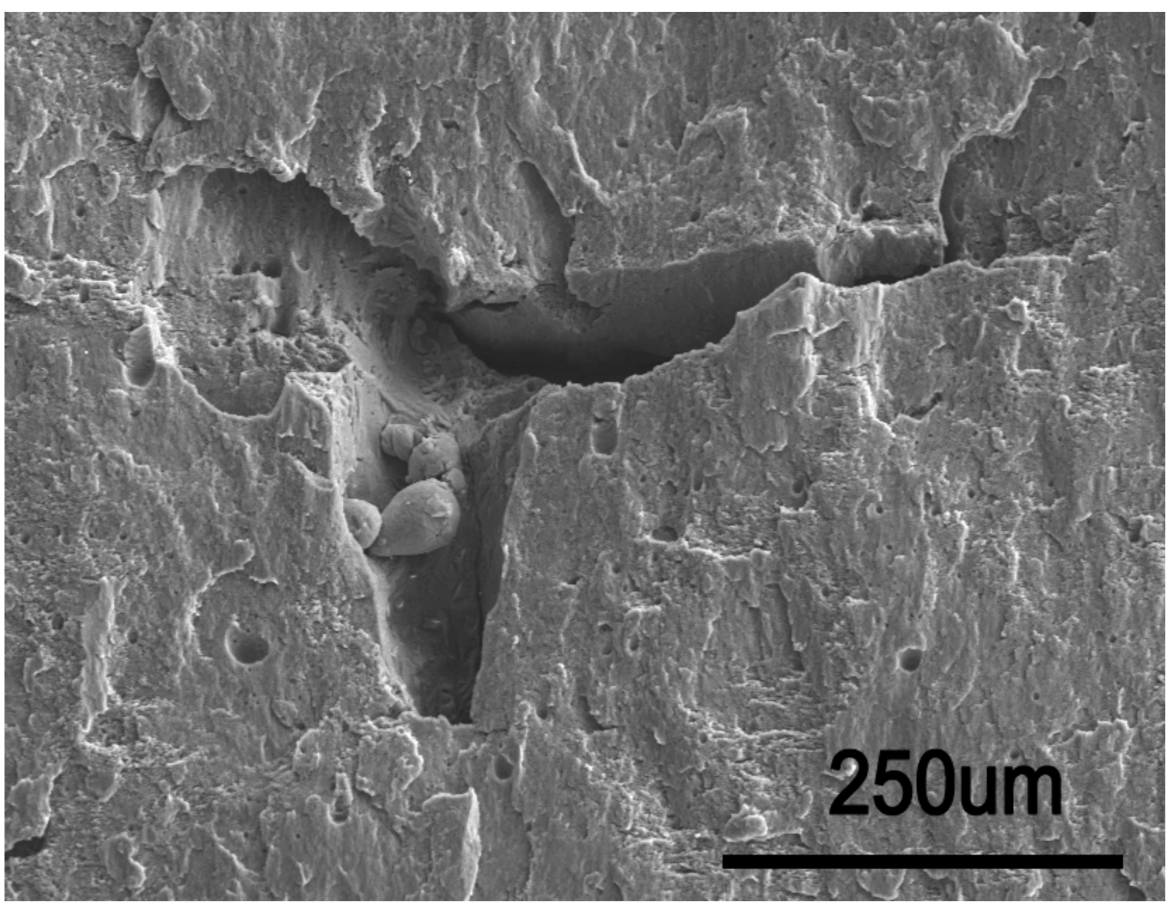

Figure 11. Lack of fusion onto the shear rupture surface of a $0^{\circ}$ specimen.

Other authors previously observed a mixed quasi-cleavage and dimpled morphology on the fracture surfaces of A356 tensile samples, in the as-cast condition or after T6, as well as of A357 produced by LPBF $[18,19]$. Jiang Wen-Ming et al., found that the dimpled morphology is dispersed uniformly under the $\mathrm{T} 6$ condition, compared to the as-cast condition.

The rupture surfaces obtained in the tensile tests exhibit the presence of numerous large voids (Figure 12), which could apparently be ascribed to a much higher porosity than that measured on metallographic sections like the one in Figure 5. Actually, crack propagation proceeds through pores located at different layers, so the number of open pores that can be observed on the rupture surfaces is not a direct measurement of the percentage porosity. Differently from previous results for Al-12Si [14], no step-like morphology was observed in this study, which corroborates the achievement of a fully densified metal structure in which hatch overlaps are successfully evened out by a correct choice of laser parameters. Dimpled rupture is the prevailing failure mode for the specimens in the present study, but it acts synergistically with other mechanisms. The dimples are equiaxed in those regions of the specimens where a tensile stress component is predominant. However, traces of plastic micro-deformation and parallel slip bands can be also detected on the surfaces. Parallel slip bands are clearly visible around the large void in Figure 12a, and they are shown at higher magnification in Figure 12d. Shear band areas have been observed before on the rupture surfaces of A356 cast tensile test specimens [18], but the additive manufactured specimens in this study show much larger slip band areas than do the cast specimens.

The rupture surfaces in Figure 12 may be ascribed to cellular fracture [14]. Cellular fracture is typical of multi-phase materials, where the various phases have different mechanical properties, as in this case $\alpha-\mathrm{Al}$ and Si precipitates that segregate along the cellular boundaries. On the cellular fracture surface, the features of both brittle and ductile fracture are present simultaneously. Each particular phase constituent cracks according to its proper decohesion mechanism. Very often in the boundaries between brittle and ductile phases, the continuity is preserved, as in the surfaces observed in Figure 12.

Some authors $[20,21]$ have affirmed that the fracture morphology of an aluminium alloy is influenced to a great extent by the type of test and by the specimen geometry; these variables change the local stress state and consequently the failure mode. The observations in this paper confirm these 
findings, since the statistical proof of anisotropy in the mechanical response is combined with the distinct failure modes that are identified depending on the combination between the build orientation, which determines the orientation of the columnar structure in the sample, and the type of load (tensile or shear) that is applied macroscopically.

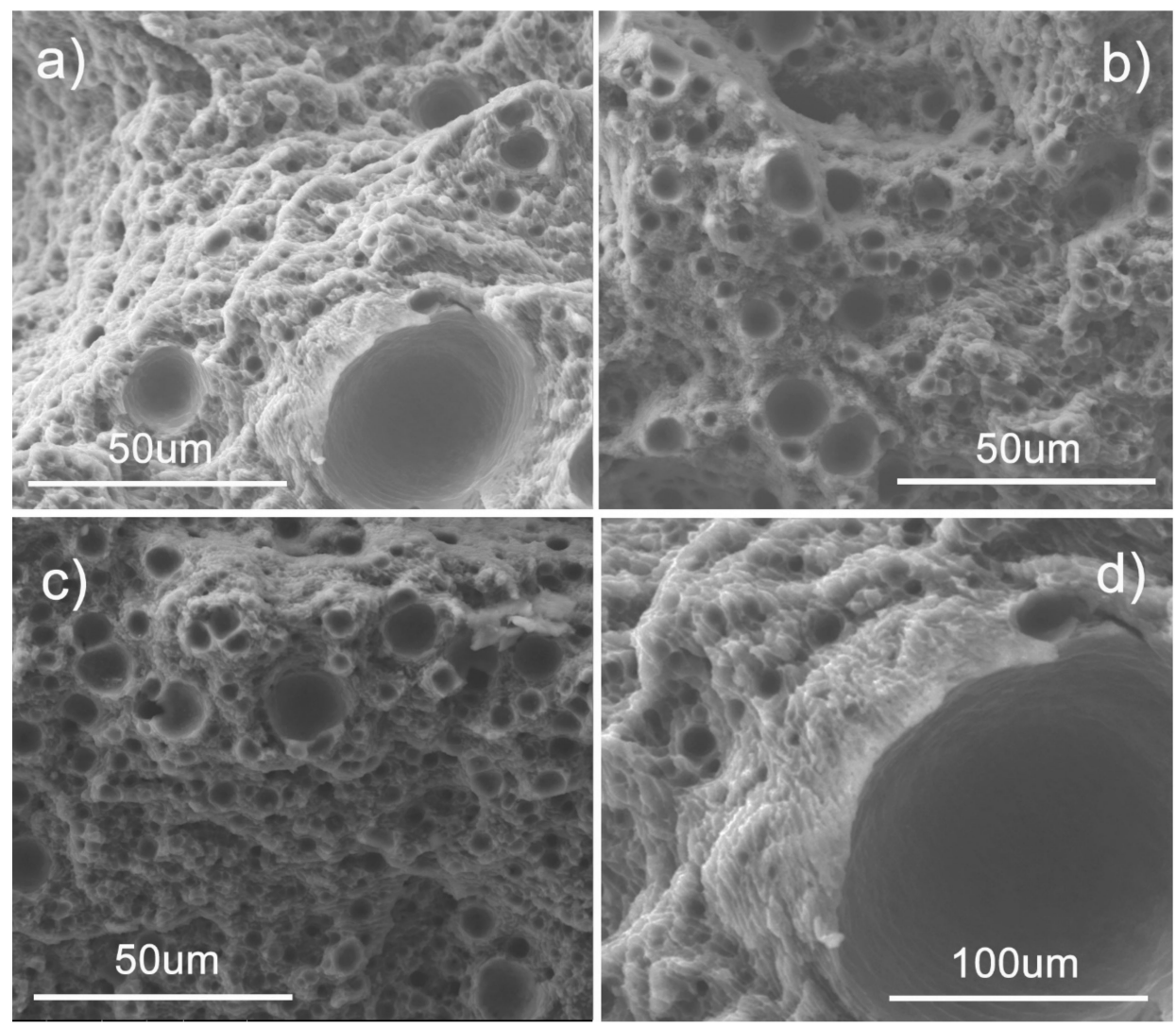

Figure 12. Rupture surfaces of A357.0 tensile test specimens: (a,d) $0^{\circ},(\mathbf{b}) 45^{\circ}$, and (c) $90^{\circ}$. Dimpled rupturing is an important failure mode for these specimens, but it acts synergistically with the formation of parallel slip bands.

\section{Conclusions}

The paper reports the characterization of A357.0 specimens produced by means of LPBF and contributes to the knowledge base of this very recent alloy. The results allow for the assertion of the following:

- The measured yield- and tensile strength values are: (i) in good agreement with those reported in literature; (ii) encouragingly comparable to those typically measured for cast parts after T6 treatment; and (iii) consistent with those reported in the datasheets by AM system producers, if the heat-treatment conditions are considered.

- Both the tensile- and the shear strength show a small (but statistically significant) raise as the direction of the specimens approaches the growth direction. The opposite trend is observed for percent total extension at fracture that is almost halved in the Z-versus in the XY direction. Vertical samples are the strongest and least ductile.

- Tensile modulus and yield strength do not show statistically significant anisotropy. Variations for different building orientations are comparable to the scatter of experimental data.

- The rupture morphology of A357.0 is influenced to a great extent by the load condition, by the specimen geometry, and by the relative orientation of loads versus the directions of inherent anisotropy in LPBF processes. Specimens show an extremely fine fibre microstructure made of 
thin grains that extend along the $Z$ direction. Both the shear- and the tensile rupture morphologies account for the anisotropy measured for the mechanical properties, since the fibre microstructure varies its reinforcing effectiveness depending on its relative orientation as compared to that of the applied stresses.

- Both for shear loads and for tensile ones, dimpled rupture is an important failure mode, but it acts synergistically with the formation of parallel slip bands. Regardless of the type of load applied macroscopically to the part, when the local stress state on the elongated grains is tensile, the rupture mode is a very fine dimple coalescence. When the fibre structure is locally subjected to shear stresses, which act tangentially to the elongated grains, rupture occurs by shear plastic flow, in which the material is spread over the surface. The extension of the plastic flow area increases as shear stresses become parallel to the build layers.

Funding: This research received no external funding.

Acknowledgments: Grateful acknowledgements are made by the author to Eng. Andrea Comin (Maserati S.pA) for the technical support and to Andrea Pasquali, general manager of ZARE Srl (Boretto, RE, Italy), for the technical support and for the construction of the specimens.

Conflicts of Interest: The author declares no conflict of interest.

\section{References}

1. Oerlikon, Additive Manufacturing the Next Industrial Revolution. Factsheet, 12.2017. Available online: https:/ / www.oerlikon.com/ecoma/files/Oerlikon-AM-Factsheet_II.pdf (accessed on 8 August 2018).

2. Herzog, D.; Seyda, V.; Wycisk, E.; Emmelmann, C. Additive manufacturing of metals. Acta Mater. 2016, 117, 371-392. [CrossRef]

3. Sercombe, T.B.; Li, X. Selective laser melting of aluminium and aluminium metal matrix composites: Review. Mater. Technol. 2016, 31, 77-85. [CrossRef]

4. Wu, J.; Wang, X.Q.; Wang, W.; Attallah, M.M.; Loretto, M.H. Microstructure and strength of selectively laser melted AlSi10Mg. Acta Mater. 2016, 117, 311-320. [CrossRef]

5. APWORKS. Scalmalloy®_-Aluminum Powder at Its Best. Available online: https://www.apworks.de/en/ scalmalloy/ (accessed on 8 August 2018).

6. Aeromet International Ltd., A20X ${ }^{\mathrm{TM}}$ POWDER. Available online: http://a20x.com/powder/ (accessed on 8 August 2018).

7. Trevisan, F.; Calignano, F.; Lorusso, M.; Pakkanen, J.; Ambrosio, E.P.; Mariangela, L.; Pavese, M.; Manfredi, D.; Fino, P. Effects of Heat Treatments on A357 Alloy Produced by Selective Laser Melting. In Proceedings of the European Congress and Exhibition on Powder Metallurgy, Hamburg, Germany, 9-13 October 2016; The European Powder Metallurgy Association: Brussels, Belgium, 2016; pp. 1-6.

8. Aversa, A.; Lorusso, M.; Trevisan, F.; Ambrosio, E.P.; Calignano, F.; Manfredi, D.; Biamino, S.; Fino, P.; Lombardi, M.; Pavese, M. Effect of process and post-process conditions on the mechanical properties of an A357 alloy produced via laser powder bed fusion. Metals 2017, 7, 68. [CrossRef]

9. CITIM GmbH. Metal Additive Manufacturing: Aluminum AlSi9Cu3, Aluminum AlSi7Mg, Aluminum AlSi10Mg. Available online: http://www.citim.de/en/metal-additive-manufacturing (accessed on 15 November 2017).

10. EOS Titanium Ti64; Material data sheet; EOS GmbH—Electro Optical Systems: Krailling, Germany, 2017.

11. SLM Solutions, 3D Metals: AlSi10Mg, AlSi12, AlSi7Mg0.6, AlSi9Cu3. Available online: https://slm-solutions. com/download-center (accessed on 27 August 2018).

12. Concept Laser: CL 30AL, CL 31AL. Available online: https://www.concept-laser.de/en/products/materials.html (accessed on 15 November 2017).

13. Kretzschmar, N. Economic Validation of Metal Powder Bed Based AM Processes. Master's Thesis, Aalto University, Helsinki, Finland, May 2015.

14. Prashanth, K.G.; Scudino, S.; Klauss, H.J.; Surreddi, K.B.; Löber, L.; Wang, Z.; Chaubey, A.K.; Kühn, U.; Eckert, J. Microstructure and mechanical properties of Al-12Si produced by selective laser melting: Effect of heat treatment. Mater. Sci. Eng. A 2014, 590, 153-160. [CrossRef] 
15. Hadadzadeh, A.; Amirkhiz, B.S.; Li, J.; Mohammadi, M. Columnar to equiaxed transition during direct metal laser sintering of AlSi10Mg alloy: effect of building direction. Addit. Manuf. 2018, 23, 121-131. [CrossRef]

16. Rao, H.; Giet, S.; Yang, K.; Wu, X.; Davies, C.H.J. The influence of processing parameters on aluminium alloy A357. Mater. Des. 2016, 109, 334-346. [CrossRef]

17. Kaufman, J.G.; Rooy, E.L. Aluminum Alloy Castings Properties, Processes, and Applications; ASM International: Almere, The Netherlands, 2004.

18. Jiang, W.; Fan, Z.; Liu, D. Microstructure, tensile properties and fractography of A356 alloy under as-cast and T6 obtained with expendable pattern shell casting process. Trans. Nonferrous Met. Soc. China 2012, 22, s7-s13. [CrossRef]

19. Rao, J.H.; Zhang, Y.; Fang, X.; Chen, Y.; Wu, X.; Davies, C.H.J. The origins for tensile properties of selective laser melted aluminium alloy A357. Addit. Manuf. 2017, 17, 113-122. [CrossRef]

20. Warmuzek, M. Aluminum-Silicon Casting Alloys: Atlas of Microfractographs; ASM International: Almere, The Netherlands, 2004.

21. Bhandarkar, M.D.; Lisagor, W.B. Metallurgical Characterization of the Fracture of Several High Strength Aluminum Alloys; National Aeronautics and Space Administration: Washington, DC, USA, 1977.

(C) 2018 by the author. Licensee MDPI, Basel, Switzerland. This article is an open access article distributed under the terms and conditions of the Creative Commons Attribution (CC BY) license (http:/ / creativecommons.org/licenses/by/4.0/). 